\title{
Penyusunan Strategi Digital dengan Pendekatan Ward dan Peppard serta Architecture Delivery Pada TOGAF versi 9 pada BMT KAS
}

\author{
Bayu Waspodo ${ }^{1}$, Asep Fajar Firmansyah ${ }^{2}$, Tuti Apriyanti ${ }^{3}$
}

\begin{abstract}
BMT KAS (Komunitas Amal Sholeh) merupakan lembaga keuangan mikro syariah dimana dalam kegiatannya BMT KAS sudah hampir seluruhnya menggunakan sistem digital akan tetapi infrastruktur digital belum sepenuhnya memadai sehingga menyebabkan Informasi belum terintegrasi dengan baik, data bersifat tersebar, sering terjadi kerangkapan data dan proses pencarian membutuhkan waktu yang lama sehingga hal ini sangat berpengaruh terhadap kinerja bisnis BMT KAS. Seharusnya BMT KAS mampu menciptakan inovasi terhadap perencanaan sistem digital secara berkelanjutan agar mampu mencapai tujuan dan sasaran bisnisnya yang juga memperhatikan peningkatan SDM. Pada penelitian ini, penulis menggunakan pendekatan Peppard dan Ward dilengkapi oleh Architecture Delivery TOGAF versi 9. Tools yang digunakan pada Peppard dan Ward yaitu Value Chain, SWOT, CSF (Critical Success Factors), Porter's Five Competitive, PEST, dan portfolio McFarlan's Strategic Grid. Sedangkan tools yang digunakan pada Architecture Delivery yaitu Archimate, Platform Teknologi dan Technology Portofolio Catalog. Hasil akhir dari penelitian ini yaitu berupa Strategi SI, Strategi TI dan Strategi Manajamen SI.
\end{abstract}

Kata kunci: Strategi Digital, Pendekatan Peppard dan Ward, TOGAF versi 9, BMT Komunitas Amal Soleh

\section{PENDAHULUAN}

Setiap perusahaan menerapkan Sistem Digital agar dapat meningkatkan keunggulan kompetitif perusahaan. Perencanaan Strategi Digital yang tepat dapat mendukung rencana dan pengembangan bisnis perusahaan sehingga dapat

Received: 5 Februari 2018; Revised: 1 Maret 2018; Accepted: 1 April 2018

B. Waspodo, Prodi Sistem Informasi Fakultas Sains dan Teknologi Universitas Islam Negeri Syarif Hidayatullah Jakarta (bayu.waspodo@uinjkt.ac.id)

A.F.Firmansyah, Prodi Sistem Informasi Fakultas Sains dan Teknologi Universitas Islam Negeri Syarif Hidayatullah Jakarta (asep.airlangga@uinjkt.ac.id)

T. Aprinyanti, Prodi Sistem Informasi Fakultas Sains dan Teknologi Universitas Islam Negeri Syarif Hidayatullah Jakarta (tuti.apriyantiii@gmail.com)

http://journal.uinjkt.ac.id/index.php/aism memenangkan persaingan bisnis. Penerapan Strategi Digital akan bermanfaat apabila selaras dengan strategi bisnis perusahaan yaitu sesuai dengan visi dan misi perusahaan.

Dalam kegiatannya BMT KAS sudah hampir seluruhnya menggunakan sistem, akan tetapi infrastruktur digital belum sepenuhnya memadai sehingga menyebabkan informasi tidak terintegrasi dengan baik, data bersifat tersebar, sering terjadi kerangkapan serta hilangnya data, dan proses pencarian membutuhkan waktu yang lama sehingga hal ini sangat berpengaruh terhadap kinerja bisnis BMT KAS. Permasalahan lain nya yaitu sumber daya manusia (SDM) yang berkompeten di bidang digital tidak ada sehingga BMT KAS harus mendatangkan pihak ketiga (luar) untuk menangani permasalahan yang terjadi di BMT KAS. Selain itu menciptakan atau membuat gerai-gerai tabungan BMT KAS juga merupakan salah satu strategi bisnis yang dijalankan oleh BMT KAS, dimana strategi ini tidak berjalan sesuai dengan tujuan perusahaan, karena hanya memfokuskan pada masalahmasalah tertentu yang paling kritis sehingga sering terjadi perubahan dan mengakibatkan penurunan produktivitas perusahaan. Melihat permasalahan BMT KAS dapat ditarik kesimpulan bahwa pemanfaatan teknologi digital di BMT KAS belum seluruhnya membantu penyelesaian berbagai masalah yang ada. Oleh sebab itu salah satu strategi yang sangat penting untuk perusahaan di era teknologi ini adalah Perencanaan Strategi Digital. Dari hal yang akan dikemukakan itu pula bahwa pengembangan sistem informasi yang tidak terencana secara sistematis akan mengakibatkan organisasi tidak memiliki prioritas proyek pengembangan sistem digital dan terkesan tambal sulam. Cara ini berdampak pada penurunan produktifitas organisasi (Ward \& Peppard, 2002)

\section{LANDASAN TEORI}

A. Perencanaan Strategis Sistem Digital

Perencanaan Strategi Digital merupakan proses identifikasi portofolio aplikasi SI berbasis komputer yang akan mendukung organisasi dalam pelaksanaan rencana bisnis dan merealisasikan tujuan bisnisnya (Ward \& Peppard, 2003).

Sebuah sistem informasi yang dibuat berdasarkan perencanaan strategi digital yang baik dapat membantu sebuah organisasi dalam proses pengambilan keputusan untuk melakukan rencana dan merealisasikan pencapaian bisnisnya. 
B. Tools Perencanaan Strategis Sistem Informasi

1). Analisis Critical Success Factor (CSF) Analisis Critical Success Factor (CSF) merupakan suatu ketentuan dari organisasi dan lingkungan yang berpengaruh pada kerberhasilan atau kegagalan (Wedhasmara, 2007).

2). Analisis SWOT

Analisis SWOT disebut juga dengan analisis KEKEPAN (kekuatan-kekuatan, kelemahankelemahan, peluang-peluang dan ancamanancaman) digunakan untuk menilai kekuatankekuatan dan kelemahan-kelemahan dari sumber daya yang dimiliki perusahaan dan kesempatankesempatan eksternal dan tantangan-tantangan yang dihadapi (Jogiyanto, 2005).

3). Analisis Value Chain

Tujuan value chain adalah menyelaraskan stakeholder untuk inisiatif perubahan tertentu, sehingga yang berpartisipasi memahami konteks fungsional dan keterlibatan arsitektur organisasi (The Open Group, 2009).

4). Analisis Porter's Five Competitive

Analisis ini digunakan untuk melihat peta persaingan yang ada pada bisnis perusahaan. Analisis ini akan melihat sejauh mana pengaruh persaingan anatara kompetitor yang ada, pendatang baru, daya tawar supplier serta daya tawar pelanggan terhadap keberlangsungan bisnis perusahaan.

5). Analisis PESTE

Menurut Peppard dan Ward (2016) analisis PESTE adalah analisa terhadap faktor lingkungan eksternal bisnis yang meliputi bidang politik, ekonomi, sosial dan teknologi, lingkungan.

6). Analisis McFarlan's Strategic Grid

Menurut Peppard dan Ward (2016) portofolio aplikasi McFarlan digunakan untuk menilai kontribusi sistem digital secara keseluruhan dan efeknya terhadap kesuksesan bisnis.

7). Archimate 3.31

Archimate menawarkan pendekatan arsitektur terintegrasi yang mendeskripsikan dan memvisualisasikan domain arsitektur yang berbeda dan hubungan serta dependensi yang mendasari.

8). Platform Decomposition Diagram

Menurut The Open Group (2009), Platform Desomposition Diagram menggambarkan platform teknologi yang mendukung operasional arsitektur sistem informasi.

9). Technology Portfolio Catalog

Menurut The Open Group (2009), tujuan dari katalog ini adalah untuk mengidentifikasi dan memelihara daftar semua teknologi yang digunakan diseluruh perusahaan, didalamnya terdapat hardware, infrastruktur software, dan aplikasi software.

\section{METODOLOGI}

A. Proses penelitian dengan acuan pendekatan Peppard dan Ward, serta Architecture Delivery TOGAF akan diuraikan menjadi dua tahapan utama yaitu, Input (Masukan) dan Ouput (Keluaran). Tahap masukan terdiri dari Analisis Lingkungan Bisnis Internal, Analisis Lingkungan Bisnis Eksternal, Analisis Lingkungan Digital Internal, dan Analisis Lingkungan Digital Eksternal. Pengolahan Architecture Delivery akan diproses secara berkesinambungan sehingga dapat diproses oleh metode lainnya dan akan masuk ke dalam tahapan Output (keluaran)

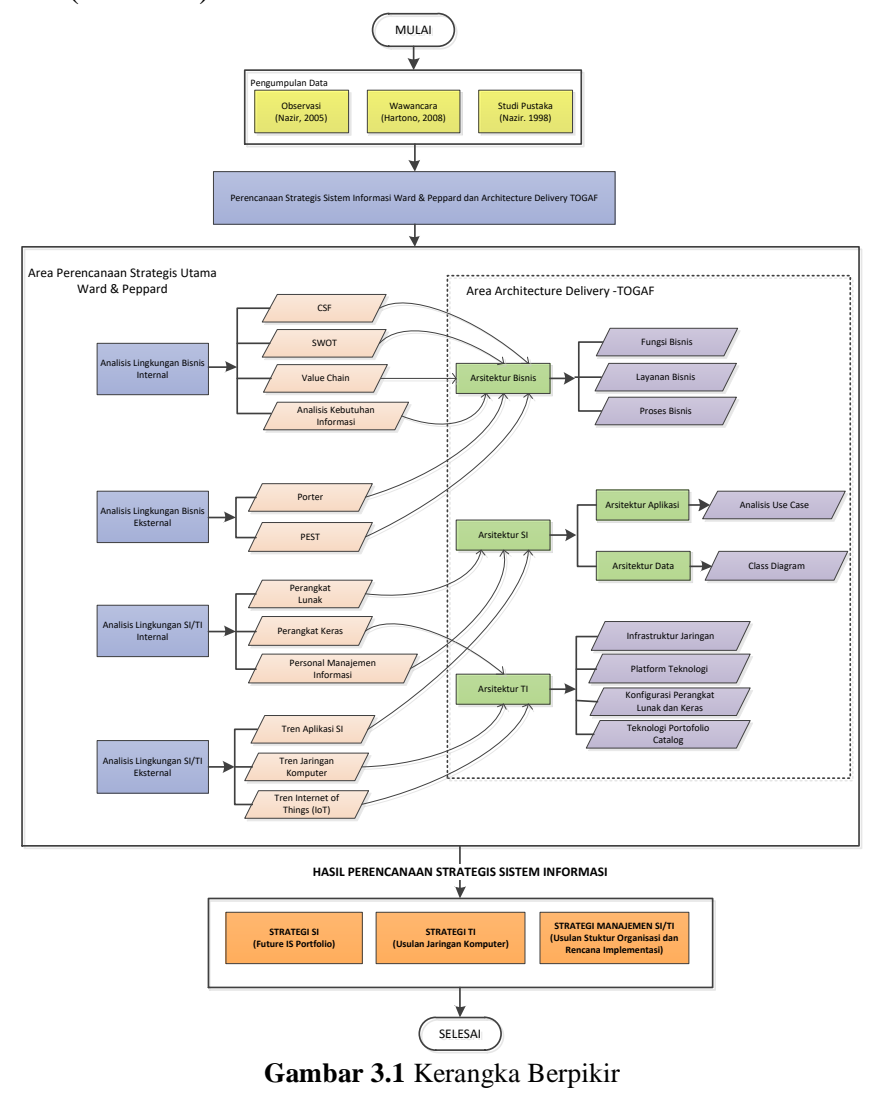

IV. ANALISIS DAN INTERPRETASI

A. Analisis Critical Success Factor (CSF)

Tabel 4.1 Analisis CSF BMT KAS 


\begin{tabular}{|c|c|c|}
\hline $\begin{array}{c}\text { Tujuan Utama } \\
\text { BMT }\end{array}$ & CSF & Measures \\
\hline $\begin{array}{l}\text { Dalam upaya } \\
\text { memberdayakan } \\
\text { umat secara } \\
\text { kebersamaan } \\
\text { melalui kegiatan } \\
\text { simpanan dan } \\
\text { pinjaman. }\end{array}$ & $\begin{array}{l}\text { Membangun produk } \\
\text { simpanan dan } \\
\text { pembiayaan dengan } \\
\text { dasar syariah dan } \\
\text { inovasi teknologi. }\end{array}$ & $\begin{array}{l}\text { Meningkatnya } \\
\text { jumlah } \\
\text { anggota. }\end{array}$ \\
\hline $\begin{array}{l}\text { Kegiatan yang } \\
\text { berdampak pada } \\
\text { peningkatan } \\
\text { ekonomi anggota } \\
\text { dan mitra ke arah } \\
\text { yang lebih baik, } \\
\text { aman dan adil. }\end{array}$ & $\begin{array}{l}\text { Melakukan } \\
\text { pembentukan sub } \\
\text { badan usaha seperti } \\
\text { koperasi, tempat } \\
\text { usaha kecil dan } \\
\text { menengah. }\end{array}$ & $\begin{array}{l}\text { Pertumbuhan } \\
\text { ekonomi } \\
\text { anggota. }\end{array}$ \\
\hline $\begin{array}{l}\text { Meningkatkan } \\
\text { kesejahteraan } \\
\text { anggota } \\
\text { khususnya pada } \\
\text { bidang } \\
\text { permodalan. } \\
\text { Dimana BMT } \\
\text { KAS menjadi } \\
\text { solusi sosial } \\
\text { ekonomi bagi para } \\
\text { pelaku usaha } \\
\text { mikro. }\end{array}$ & $\begin{array}{l}\text { Ketersediaan dana } \\
\text { ysng dapat } \\
\text { dimanfaatkan } \\
\text { semaksimal } \\
\text { mungkin. }\end{array}$ & $\begin{array}{l}\text { Adanya } \\
\text { peningkatan } \\
\text { permodalan. }\end{array}$ \\
\hline
\end{tabular}

\section{Analisis PESTE}

PESTE merupakan teknik dalam manajemen strategis yang digunakan untuk meliat faktor-faktor lingkungan luar yang berpengaruh terhadap suatu hal (perusahaan, proyek dan masalah)

\section{B. Analisis Value Chain}

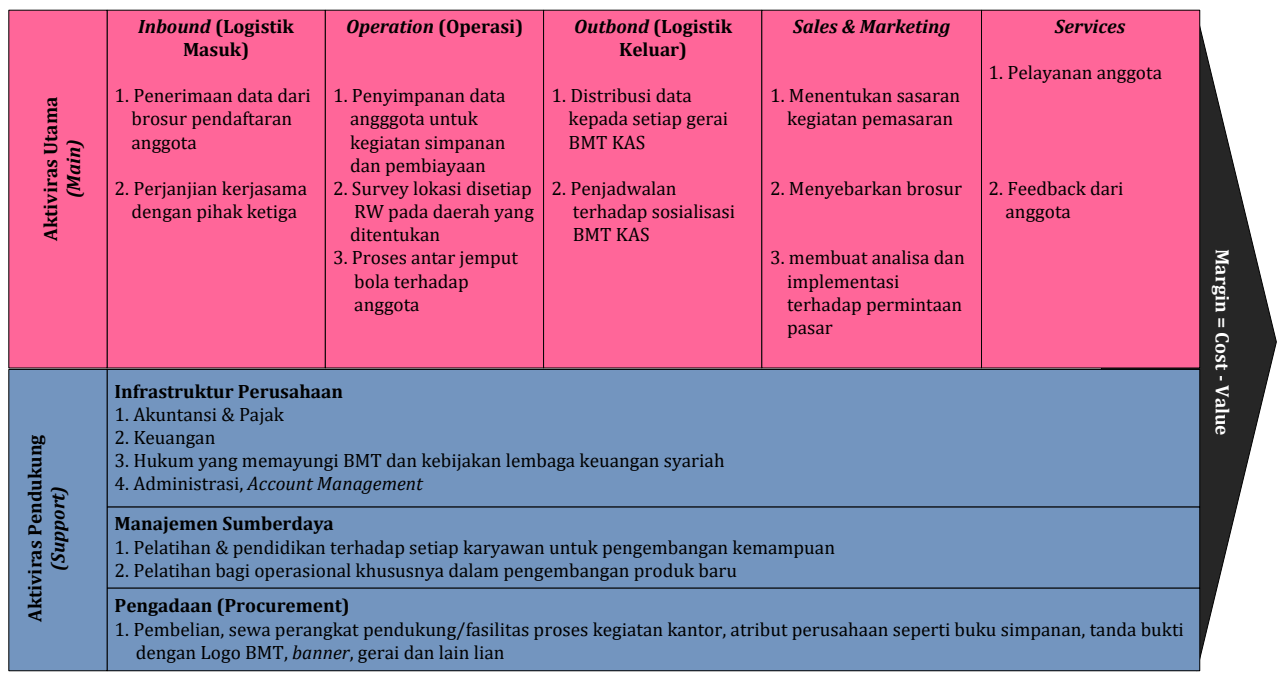

Gambar 4.1 Analisis Value Chain

\section{B. Current Portfolio Application}

Tabel 4.2 Current Portfolio Aplication

\begin{tabular}{cc}
\hline \hline STRATEGIC & HIGH POTENTIAL \\
\hline Blog BMT KAS & \\
MicSys (Micro System) & Microsoft Office \\
KEY OPERATION & SUPPORT \\
\hline \hline
\end{tabular}

\section{Future Portofolio Aplikasi BMT KAS}

Tabel 4.3 Future Portofolio Aplikasi

\begin{tabular}{ll}
\hline \hline \multicolumn{1}{c}{ STRATEGIC } & \multicolumn{1}{c}{ HIGH POTENTIAL } \\
\hline SI Pelayanan Informasi & SI Auditing, SI \\
Berbasis Website & Pendukung Keputusan \\
SI Simpan Pinjam, SI Keu, & SI Pelayanan Informasi \\
SI Kepegawaian & Berbasis SMS Gateway \\
KEY OPERATION & SUPPORT \\
\hline \hline
\end{tabular}

\section{Struktur Organisasi Usulan}




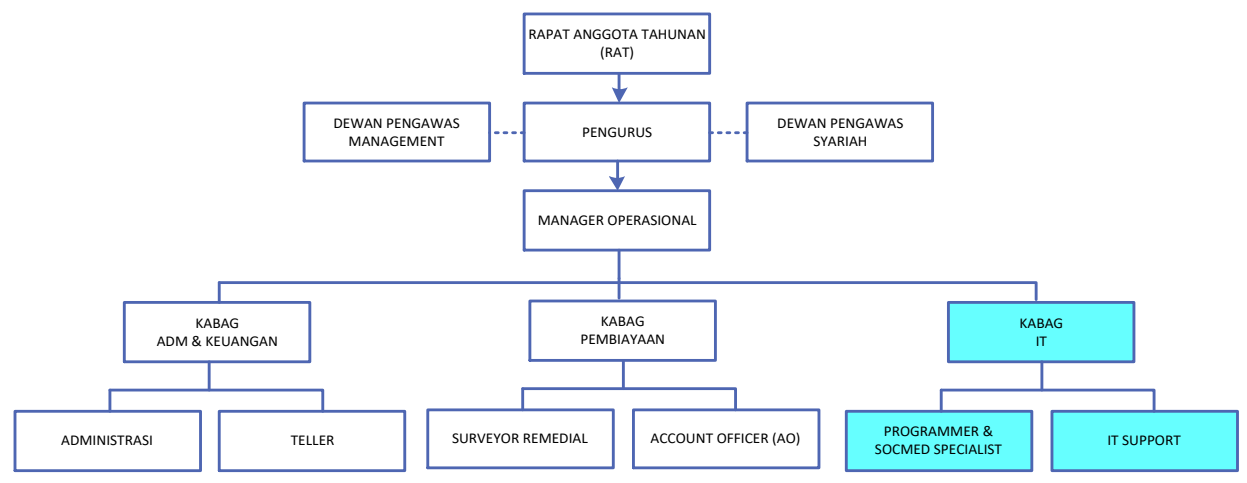

Gambar 4.2 Struktur Organisasi Usulan

\section{E. Jaringan Usulan}

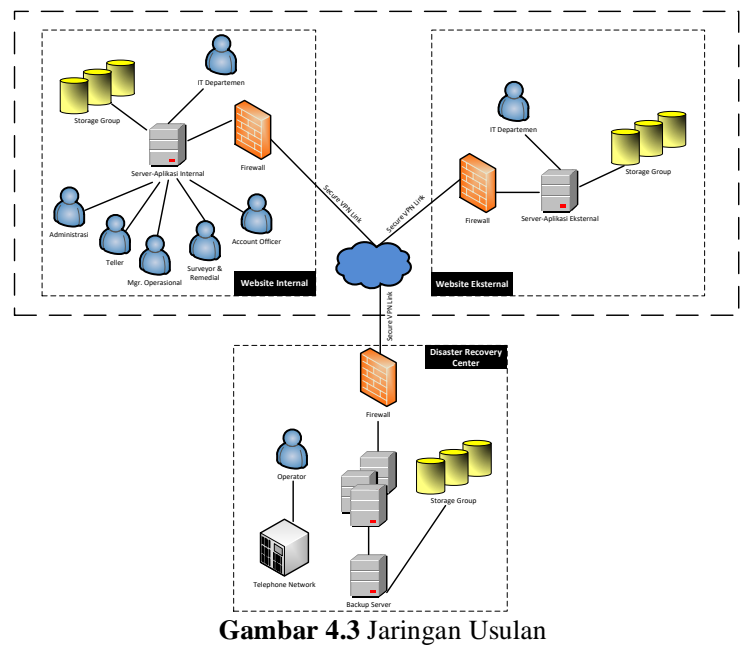

\section{F. Platform Decomposition Diagram}

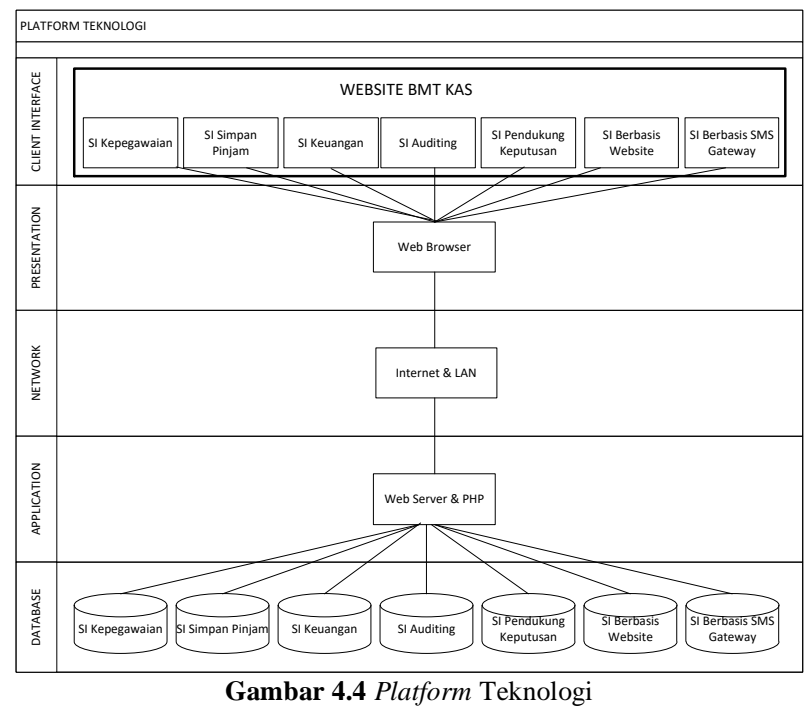

G. Roadmap Aplikasi

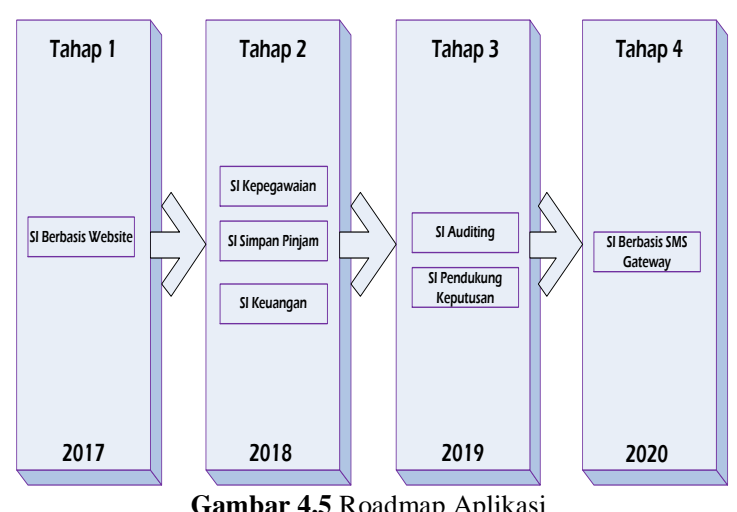

\section{PENUTUP}

\section{A. Kesimpulan}

Berdasarkan uraian dan pembahasan pada bab sebelumnya maka pada bab ini diambil kesimpulan bahwa:

1. Menghasilkan analisis berupa perencanaan strategis sistem informasi yang didukung oleh arsitektur enterprise dengan menggunakan TOGAF. Perencanaan strategis yang sudah dianalisis menghasilkan sebuah Strategi SI, Strategi TI dan Strategi Manajemen SI.

2. Adanya usulan infrastruktur digital berupa arsitektur teknologi dengan konfigurasi server baru yang bersinergis dengan strategi digital yang dapat mengintegrasikan antar aplikasi untuk kebutuhan internal dan eksternal, namun juga proteksi terhadap resiko kehilangan data akibat bencana atau hal lain dengan penerapan DRP (Disaster Recovery Plan).

3. Pada analisis yang sudah dilakukan didapat usulan struktur organisasi mengenai SDM yang dapat mendukung kegiatan operasional BMT KAS. Adapun usulan struktur organisasinya pada bagian teknologi informasi yaitu, Programmer \& Social Media Specialist dan IT Support.

B. Saran

1. Pihak manajemen perlu melakukan evaluasi perencanaan strategi digital secara berkala untuk mengevaluasi dan 
mengontrol penggunaan teknologi digital oleh sumber daya yang ada.

2. Pada tahapan selanjutnya perlu suatu kegiatan rancang bangun terhadap rencana strategi digital yang mendukung adanya realisasi dari pendekatan Ward \& Peppard \& Architecture Delivery pada TOGAF, sehingga mendukung realisasi dari perencanaan strategi bagi perusahaan.

3. Pembahasan lebih lanjut dengan penerapan peningkatan perusahaan melalui pendekatan Ward and Peppard untuk perencanaan strategi digital hendaknya perusahaan mulai mempertimbangkan kebijaksanaan untuk kelangsungan bisnis perusahaan, disertai pengawasan dengan analisis kelayakan investasi sehingga dapat menjadi indikator pengendalian evaluasi paska implementasi PSSI.

\section{REFERENSI}

[1]. Jogiyanto, HM. 2005. Sistem Informasi Stratejik. Yogyakarta: ANDI.

[2]. The Open Group. 2009. Achimate 2.1 Specification. San Fransisco: The Open Group.
[3]. The Open Group. 2009. TOGAF Versi 9. San Fransisco: The Open Group.

[4]. The Open Group. 2009. TOGAF Versi 9: Sample Catalogs, Matrices and Diagram. San Fransisco: The Open Group.

[5]. Peppard, J. \& Ward, J (2016). The Strategic Management of Information Systems, 4th Edition, Wiley.

[6]. Ward, John and Peppard Joe. 2002. Strategic Planning for Information System, third Edition. England: John Wiley \& Sons Ltd. England.

[7]. Ward, John and Peppard Joe. 2003. Strategic Planning for Information System $3^{\text {rd }}$ ed. John Wiley \& Sons Ltd. England.

[8]. Wedhasmara, A. 2007. Langkah-langkah Perencanaan Strategis Sistem Informasi dengan Menggunakan Metode Ward \& Peppard. Universitas Sriwijaya. Palembang.. 